\title{
OS CENTROS REFERÊNCIA DE ATENDIMENTO À MULHER EM SITUAÇÃO DE VIOLÊNCIA E A EXPERIÊNCIA DO PRO PAZ MULHER (BELÉM-PARÁ) // Luanna Tomaz Souza ${ }^{1}$, Milene Maria Xavier Veloso²e
}

Ivonete Pinheiro ${ }^{3}$

\author{
Palavras-chave \\ Lei Maria da Penha / Pro Paz / prevenção / centros de \\ referência
}

HIIIIIIIIIIIIIIIIIIIIIIIIIIIIIIIII

\section{Sumário}

1 Introdução

2 A prevenção e a assistência na Lei Maria da Penha

3 Os centros especializados para mulheres em situação de violência e o surgimento do Pro Paz Mulher Do setor social ao Pro Paz Mulher: permanências e limites de uma política

5 Considerações finais

6 Referências

\section{Resumo}

O Programa de governo chamado Pro Paz, surgiu em 2004, no Estado do Pará, tendo como eixo central uma proposta de promoção da "cultura de paz e a não violência". Como parte desse programa foi implantado, em 2014, o chamado Pro Paz Mulher com objetivo de articular ações de polícia, perícia, atendimento psicossocial e outros serviços e projetos voltados à mulher em situação de violência. É importante refletir acerca dessa experiência para se compreender os limites e potencialidades das experiências brasileiras de centros de referência discutindo em que maneira se aproximam e se distanciam dos contornos legais. Desta feita, a partir de uma pesquisa dedutiva, de base documental, bibliográfica e empírica, avaliou-se de que forma o Pro Paz Mulher se constrói enquanto centro de referência nos termos dos marcos legais, em especial: a Lei Maria da Penha, a Norma Técnica de Uniformização dos Centros de Referência de Atendimento à MuIher em Situação de Violência e a Política Nacional de Enfrentamento à Violência contra as Mulheres.

\footnotetext{
1 Professora da Faculdade de Direito e do Programa de Pós-Graduação em Direito da Universidade Federal do Pará (UFPA). Doutora em Direito (Universidade de Coimbra). Pesquisadora do GEPEM (Grupo de Estudos e Pesquisas 'Eneida de Moraes' - Sobre Mulher e Relações de Gênero) e do NEIVA (Núcleo de Estudos Estratégicos da Violência na Amazônia). Coordenadora da Clínica de Atenção à Violência da UFPA (CAV).

2 Professora da Faculdade de Psicologia da Universidade Federal do Pará (UFPA). Doutora pelo programa de Pós Graduação em Teoria e Pesquisa do Comportamento (PPGTPC-UFPA). Coordena o projeto de pesquisa "Violência contra crianças e adolescentes: indicadores e estratégias de enfrentamento", atualmente faz parte da Assessoria de Diversidade e Inclusão Social vinculada ao gabinete da reitoria da Universidade Federal do Pará, é colaboradora na Clínica de Atenção à Violência - CAV/UFPA e no Núcleo de Estudos Estratégicos da Violência na Amazônia (NEIVA).

3 Cientista Social. Mestranda em Antropologia no Programa de Pós-graduação em Antropologia e Sociologia- PPGSA/UFPA. Cursando Especialização em Controle, Prevenção e Intervenção na Violência no Instituto de Ciências da Saúde- ICS/UFPA. Associada do Grupo de Estudos e Pesquisas ‘Eneida de Moraes'- Sobre Mulher e Relações de Gênero -GEPEM. Membra da Clínica de Atenção à Violência da CAV/UFPA.
} 


\section{THE EXPERIENCE OF THE PRO PEACE WOMAN: REFLECTIONS ABOUT THE LIMITS AND POTENTIALITIES OF THE INTEGRATED CENTERS // Luanna Tomaz Souza, Milene Maria Xavier Veloso e Ivonete}

\section{Pinheiro}

\section{Keywords}

Maria da Penha Law / Pro Paz / prevention /

reference centers

HIIIIIIIIIIIIIIIIIIIIIIIIIIIIIIIIII

\begin{abstract}
The Pro Paz government program was launched in 2004 in the state of Pará, with a central theme of promoting a culture of peace and non-violence. As part of this program, the so-called Pro Paz Mulher was implemented in 2014 with the objective of articulating police actions, expertise, psychosocial care and other services and projects aimed at women in situations of violence. It is important to reflect on this experience in order to understand the limits and potentialities of the Brazilian experiences of centers of reference, discussing how they approach and distance themselves from the legal contours. Based on a deductive, documentary, bibliographical and empirical research, it was evaluated how Pro Paz Mulher is being built as a reference center in terms of legal frameworks, especially in "Maria da Penha Law", the Technical Standard of Uniformization of Reference Centers for Assistance to Women in Situation of Violence and the National Policy to Combat Violence against Women.
\end{abstract}




\section{Introdução}

O programa Pro Paz foi criado em 2004, no primeiro mandato do Governador Simão Jatene, com o objetivo de articular, fomentar e alinhar políticas públicas voltadas para a infância, adolescência e juventude, visando a garantia dos direitos, o combate e a prevenção da violência. Desde então as ações acontecem em parceria com os mais diversos setores da sociedade, governamentais e não governamentais. ${ }^{4} \mathrm{Em} 2013$, foi transformado em política de Estado, regulamentado pela Lei $n^{\circ} 7.773$, tendo como alvo a institucionalização da "cultura de paz" e da "não violência" como ações de política pública. Dessa forma a gestão do Pro Paz passou a ser formada por um Comitê Gestor que reúne membros do Poder Executivo, Legislativo, Judiciário e a Universidade Federal do Pará (UFPA). Em 2015, o Pro Paz passou a ser Fundação, criada pela Lei $\mathrm{n}^{\circ} 8.097$, ganhando status de entidade da administração direta, vinculada ao Gabinete do Governador.

Atualmente a Fundação articula cerca de 13 (treze) projetos que estão em funcionamento ${ }^{5}$, um deles, o chamado Pro Paz Integrado (PPI), foi organizado como um serviço, que reúne em um mesmo espaço físico, a assistência médica/hospitalar, psicossocial, policial e medicina legal, orientados por uma ação interdisciplinar e atendimento humanizado às crianças e adolescentes em situação de violência. O PPI desenvolveu-se como desdobramento da experiência consolidada anteriormente pelo Projeto "Girassol", da Fundação Santa Casa de Misericórdia do Pará, através de um processo de articulação com instituições ligadas à defesa dos direitos das crianças e dos adolescentes, para elaboração de um projeto junto à Rede Estadual de Enfrentamento à Violência Sexual de Crianças e Adolescentes. 0 objetivo era reunir em um único espaço os serviços necessários para atenção integral a esse público. A proposta principal era de evitar a revitimização das crianças vítimas de violência, resultante da falta de integração dos serviços de atendimento a partir do processo de denúncia. Nos termos da Lei ${ }^{\circ} 8.097 / 2015$ :

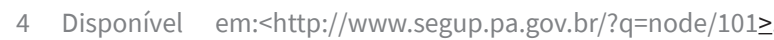
Acesso em: 05 jan. 2018.

5 Pro paz nos Bairros, Pro Paz Integrado, MOVER, Pro Paz Cidadania, Pro Paz Juventude, Pro Paz nas Escolas, Pro Paz Comunidade, Pro Paz Mulher, Pro Paz Infra, Unidade Integrada Pro Paz, Pro Paz Arte e Cultura, Pro Paz Esporte e Lazer e Fabricação de ídolos.
}

Art. $2^{\circ}$ O Programa PRO PAZ - PRESENÇA VIVA tem por finalidade fomentar, articular, coordenar, alinhar e integrar as políticas públicas para a infância, adolescência, juventude e pessoas em situação de vulnerabilidade social por meio de ações de inclusão social, promoção da cidadania e disseminação da cultura da paz no Estado do Pará.

O Pro Paz Mulher (PPM), que faz parte do Pro Paz Integrado (PPI), foi criado, em 2014, para oferecer um serviço especializado de atendimento integral, qualificado e humanizado às mulheres em situação de violência doméstica, familiar e sexual. O PPM articula em um mesmo espaço, ações de polícia, perícia, atendimento psicossocial e outros serviços e projetos voltados à mulher em situação de violência. Não há muita clareza, contudo, sobre os contornos legais desta política no âmbito do enfrentamento às violências cometidas contra as mulheres. $\mathrm{O}$ objetivo desse artigo é avaliar de que forma o Pro Paz Mulher se amolda nas diretrizes estabelecidas para os centros integrados de atendimento às mulheres em situação de violência e pela Lei Maria da Penha, Lei n ${ }^{\circ} 11.340$, de 7 de agosto de 2006.

A Lei Maria da Penha afirma que a União, o Distrito Federal, os Estados e os Municípios poderão criar e promover, no limite das respectivas competências, a criação de serviços como os centros de atendimento integral e multidisciplinar para mulheres e respectivos dependentes em situação de violência doméstica e familiar (art.35, I). Isso mostra a relevância deste serviço. De acordo com a Norma Técnica de Uniformização dos Centros de Referência de Atendimento à Mulher em Situação de Violência (SPM, 2006b, p. 15):

Os Centros de Referência são espaços de acolhimento/atendimento psicológico, social, orientação e encaminhamento jurídico à mulher em situação de violência, que proporcione o atendimento e o acolhimento necessários à superação da situação de violência ocorrida, contribuindo para o fortalecimento da mulher e o resgate da sua cidadania.

É interessante compreender como esses centros de referência tem se implementado pelo país. Para a realização dessa pesquisa, que toma como foco o serviço paraense, partir-se-á de um método dedutivo, que analisa de que forma este espaço se amolda às nor- 
mas voltadas ao enfrentamento à violência doméstica e familiar cometida contra as mulheres, em especial a Lei Maria da Penha, a Norma Técnica de Uniformização dos Centros de Referência de Atendimento à MuIher em Situação de Violência e a Política Nacional de Enfrentamento à Violência contra as Mulheres. Utiliza-se também uma metodologia feminista, na perspectiva de transformação das instituições/estruturas investigadas para que afrontem as desigualdades entre homens e mulheres, reconhecendo limites, mas também apresentando potencialidades (Souza, 2016).

Para o desenvolvimento do estudo realizou-se pesquisa bibliográfica, em pesquisadoras sobre o tema das políticas públicas e da violência doméstica; documental, nas diretrizes normativas para o tema; e empírica, através de visitas ao espaço e entrevistas com a delegada da Delegacia Especializada de Atendimento à Mulher (DEAM) e a coordenadora do Pro Paz Mulher. As visitas envolveram uma observação etnográfica, destacando-se o funcionamento do serviço e as entrevistas foram semiestruturadas, possibilitando compreender melhor de que forma estas profissionais percebem o espaço.

É de fundamental importância analisar os limites das experiências de atendimento integral às mulheres em situação de violência no Brasil, tendo em vista a precariedade como muitos desses serviços têm se desenvolvido no país (CPMI, 2013). Ademais, é importante que esse equipamento, assim como os demais que são criados no país, atue efetivamente de forma a consolidar a implementação de uma política nacional de enfrentamento à violência contra a mulher, sendo necessário, para que se alcance esse fim a padronização de diretrizes e procedimentos de funcionamento do serviço assegurando a qualidade do serviço, a produção nacional de dados e o necessário monitoramento.

\section{A prevenção e a assistência na lei Maria da Penha}

A prevenção é um viés fundamental no enfrentamento de qualquer problema. Para prevenir a violência doméstica e familiar cometida contra a mulher é necessário compreender que esta é um fenômeno cultural que está imbricado em nossa sociedade e exige ações complexas para além do viés punitivo.
Essa percepção também tem se consolidado internacionalmente. A Comissão Interamericana de Direitos Humanos, na análise do caso Maria da Penha, em 2001, em seu Informe n. ${ }^{\circ}{ }^{54^{6}}$, responsabilizou o Brasil por negligência, omissão e tolerância em relação à violência doméstica recomendando, dentre outras coisas ${ }^{7}$ :

4. Prosseguir e intensificar o processo de reforma que evite a tolerância estatal e o tratamento discriminatório com respeito à violência doméstica contra mulheres no Brasil. A Comissão recomenda particularmente o seguinte:

a. Medidas de capacitação e sensibilização dos funcionários judiciais e policiais especializados para que compreendam a importância de não tolerar a violência doméstica;

b. Simplificar os procedimentos judiciais penais a fim de que possa ser reduzido o tempo processual, sem afetar os direitos e garantias de devido processo;

c. O estabelecimento de formas alternativas às judiciais, rápidas e efetivas de solução de conflitos intrafamiliares, bem como de sensibilização com respeito à sua gravidade e às consequências penais que gera;

d. Multiplicar o número de delegacias policiais especiais para a defesa dos direitos $d a$ mulher e dotá-las dos recursos especiais necessários à efetiva tramitação e investigação de todas as denúncias de violência doméstica, bem como prestar apoio ao Ministério Público na preparação de seus informes judiciais.

e. Incluir em seus planos pedagógicos unidades curriculares destinadas à compreensão da importância do respeito à mulher e a seus direitos reconhecidos na Convenção de Belém do Pará, bem como ao manejo dos conflitos intrafamiliares.

$6 \mathrm{CIDH}$. Relatório $n^{\circ}$ 54/01. Caso 12.051. Disponível em: <www.cidh. org/annualrep/2000port/12051.htm>. Acesso em: 12 jun. 2018.

7 Segundo a Opinião Consultiva n.13 (OC 13-93), este relatório tem caráter diferente do anterior. Tem um caráter definitivo e sua publicação pode ser entendida como uma alternativa de execução da resolução definitiva adotada pela Comissão e, portanto, incompatível com o envio à Corte. 
O Termo de Referência - Enfrentamento da Violência contra as Mulheres ${ }^{8}$ (SPM, 2014) da Secretaria de Política para as Mulheres afirma que a prevenção inclui não somente ações educativas, mas também culturais que disseminem atitudes igualitárias e valores éticos de irrestrito respeito às diversidades de gênero, raça/etnia, geracionais e de valorização da paz. No tocante à violência doméstica, a prevenção deverá focar na mudança de valores, em especial no que tange à cultura do silêncio quanto à violência contra as mulheres no espaço doméstico e à banalização do problema pela sociedade.

Nesse sentido, a Lei Maria da Penha tem um grande mérito, pois aposta em diferentes mecanismos para prevenção da violência, reconhecendo suas raízes culturais e estruturais de nossa sociedade. Em seu art. $8^{\circ}$, reafirma a importância de ações como: a integração operacional dos órgãos das áreas de segurança pública, assistência social, saúde, educação, trabalho e habitação e a capacitação de seus agentes; a promoção de estudos e pesquisas, estatísticas e outras informações relevantes, com perspectiva de gênero e de raça ou etnia, bem como de campanhas educativas a sociedade em geral. Além disso, ressalta o respeito nos meios de comunicação social evitando a imagem de papéis estereotipados e da incitação à violência; a implementação de atendimento policial especializado para as mulheres, em particular nas Delegacias de Atendimento à Mulher. Há também o destaque, para os currículos escolares de todos os níveis de ensino, de conteúdos relativos aos direitos humanos, à equidade de gênero, raça ou etnia e ao problema da violência doméstica e familiar contra a mulher.

O desafio de se estabelecer uma articulação entre as várias instituições é facilitado pelo fato da Lei trazer diretrizes para a atuação das entidades e pautar a necessidade de integração em âmbito municipal, estadual e federal. Ainda há, todavia, a necessidade de um esforço maior na estruturação de políticas de prevenção, em detrimento do enfoque exclusivo nas ações de responsabilização criminal. A pesquisa do

8 Disponível em: <http://www.spm.gov.br/subsecretaria-de-enfrentamento-a-violencia-contra-as-mulheres/pacto/documentos/ tr-enfrentamento-da-violencia-contra-a-mulher.pdf>. Acesso em: 12 jun. 2018
DataSenado de $2015^{9}$ revelou que $100 \%$ das mulheres já ouviu falar na Lei Maria da Penha e 56\% acredita que depois da Lei a mulher está mais protegida. Esse é um dado que mostra o quanto a Lei se difundiu e tornou-se importante na sociedade, mas ainda precisa superar algumas barreiras.

É interessante observar o crescimento de estudos acerca do fenômeno, principalmente no ambiente universitário, ${ }^{10}$ além da produção de cartilhas e eventos sobre a temática (Bianchini, 2014). Todavia, há muita dificuldade em se cumprir esse objetivo nas escolas. O Projeto de Lei 7627, da deputada Janete Rocha Pietá (PT-SP), de 2010, altera a Lei nº 9.394 de 20 de dezembro de 1996 que estabelece as diretrizes e bases da educação nacional, para incluir no currículo oficial da rede de ensino a obrigatoriedade da temática de gênero e suas relações intra e interpessoais, recebe muita resistência à sua aprovação, principalmente por parte de setores religiosos. ${ }^{11}$

Ressalte-se, entretanto, o esforço da Secretaria de Política para as Mulheres com a edição do Programa “Gênero e Diversidade na Escola”, lançado em parceria com o Conselho Britânico, para formação na temática de gênero e feminismo do corpo docente da rede pública de educação. A despeito disso, recentemente, o Conselho Nacional de Educação retirou gênero e orientação sexual de diversos pontos da Base Nacional Comum Curricular (BNCC) e alterou, principalmente, o conteúdo relacionado ao ensino religioso. ${ }^{12}$ Pelo país, vê-se um crescimento de posturas conservadoras e diminui-se cada vez mais o espaço de debate acerca das desigualdades de gênero nas escolas, inclusive

9 Disponível em: https://www12.senado.leg.br/noticias/arquivos/2015/08/10/violencia-domestica-e-familiar-contra-a-mulher. Acesso em: 12 jun. 2018.

10 Um bom exemplo de espaço de formação existente são os grupos de "promotoras legais", inicialmente implementado pelo grupo Themis - assessoria e estudos de género, em 1993 e, atualmente, difundido no país que busca compartilhar informações sobre violência contra a mulher.

11 Ricardo, P. Urgente: Congresso pode aprovar a ideologia de género como meta da educação, Disponível em: <https://padrepauloricardo.org/blog/urgente-congresso-pode-aprovar-a-ideologia-de-genero-como-meta-da-educacao>. Acesso em: 12 jun. 2018.

12 G1. CNE retira gênero e orientação sexual da Base Curricular. Disponível em: Leia mais: https://oglobo.globo.com/sociedade/ educacao/cne-retira-genero-orientacao-sexual-da-base-curricular-22179063\#ixzz51AYnFV2X. Acesso em: 12 jun. 2018. 
com propostas de proibição e punição para professores/as que decidiram pautar essas temáticas. ${ }^{13}$

É imperativo também destacar a importância dos meios de comunicação nesse processo que ainda reproduzem uma visão estereotipada das mulheres. Segundo o Projeto Global de Monitoramento de Mídia de 2010 (Global Media Monitoring Project-GMMP) 48\% de todas as matérias reforçam estereótipos de gênero. As mulheres são identificadas nos noticiários por seus relacionamentos familiares cinco vezes mais que os homens. ${ }^{14}$ No caso das mulheres negras a situação é ainda pior. Segundo Winch e Escobar (2012), o discurso publicitário destina espaços e posições subalternas para as negras, reproduz estereótipos e desigualdades, legitimando valores deturpados da vida social.

Molina e Gomes (2012) chamam atenção para o fato de que todos os esforços preventivos são direcionados a quem comete o crime, principalmente através da ameaça da pena, sem contemplar todas as formas de prevenção. Para os autores, haveria três formas de prevenção: primária, secundária e terciária. A primeira ocorre com a inserção do indivíduo no meio social através da educação, da habitação, do trabalho, da melhoria na qualidade de vida. A segunda atuaria mais tarde com a exteriorização do conflito através de política legislativa e a ação do sistema de justiça. A prevenção terciária alcança o/a condenado/a para evitar que reincida através de sua ressocialização. Os autores também identificam a chamada prevenção vitimária destinada a verificar o potencial da vítima, sugerindo uma intervenção nos grupos de vítimas potenciais. Desta feita, os programas de prevenção devem ser dirigidos ao agressor, às vítimas e a toda a sociedade.

Segundo Jorge-Birol (2007), para a prevenção e a diminuição dos crimes são necessárias medidas alternativas às repressivas e interdisciplinares. Quando falamos em políticas de combate à ao crime se pensa

13 REVISTA FORUM. Apesar de vetado pelo STF, municípios proíbem discussão de gênero nas escolas. Disponível em: https://www.revistaforum.com.br/2017/12/10/apesar-de-vetado-pelo-stf-municipios-proibem-discussao-de-genero-nas-escolas/. Acesso em: 12 jun. 2018. 14 AGÊNCIA PATRÍCIA GALVÃO. Relatório preliminar do Projeto Global de Monitoramento de Mídia de 2010. Disponível em: http://agenciapatriciagalvao.org.br/mulher-e-midia/noticias-midia/08032010-quem-fez-a-noticia-em-2010/..Acesso em: 12 jun. 2018. muito na atuação policial, contudo, se precisa refletir sobre outros aspectos, tais como os mecanismos legais disponíveis, o atendimento realizado pelos órgãos do sistema de justiça, as ações educativas e a vontade política das/os dirigentes.

Além da preocupação com a prevenção, a Lei Maria da Penha traz um rol de medidas voltadas a proteção das mulheres de uma eventual agressão ou a assisti-las após a violência. Estas alargam o espectro de atuação judicial, sendo reconhecidamente um dos principais avanços legais (OBSERVE, 2011).

No âmbito da assistência, nos termos do art. $9^{\circ}$, tanto o/a juiz/a quanto a rede de atendimento podem incluir a mulher em programas de assistência seguindo diretrizes como as do Sistema Único de Saúde ${ }^{15}$, do Sistema Único de Segurança Pública ${ }^{16}$ e do Sistema Único de Assistência Social. ${ }^{17}$ Tais medidas são importantes para que a mulher tenha sua autonomia econômica e emocional garantidas. $\mathrm{O}$ artigo garante inclusive sua manutenção no trabalho, na medida em que este é um direito fundamental previsto na Constituição (art. $\left.6^{0}\right)^{18}$ e no art. 11 da CEDAW. ${ }^{19}$

Além das medidas de assistência, a Lei também inova ao elencar um rol exemplificativo de mecanismos de urgência voltados a impedir que novas situações de violência ocorram. São medidas que se dividem entre as que obrigam o agressor e àquelas voltadas à ofendida e são um dos aspectos mais conhecidos da Lei:

Das Medidas Protetivas de Urgência que Obrigam o Agressor

15 Com diretrizes estabelecidas na Lei $\mathbf{n}^{\circ} \mathbf{8 . 0 8 0}$, de $\mathbf{1 9}$ de setembro de 1990.

16 Apesar de estar mencionado na Lei, ainda não foi aprovado o Projeto de Lei 3.734/2012, que institui o Sistema Único de Segurança Pública (SUSP).

17 Instituído pela Lei Orgânica da Assistência Social (LOAS), nº 8.742 .

18 Art. $6^{\circ}$ São direitos sociais a educação, a saúde, a alimentação, o trabalho, a moradia, o lazer, a segurança, a previdência social, a proteção à maternidade e à infância, a assistência aos desamparados, na forma desta Constituição.

19 Art. 11 Os Estados-partes adotarão todas as medidas apropriadas para eliminar a discriminação contra a mulher na esfera do emprego a fim de assegurar, em condições de igualdade entre homens e mulheres, os mesmos direitos, em particular: a) o direito ao trabalho como direito inalienável de todo ser humano (...). 
Art. 22. Constatada a prática de violência doméstica e familiar contra a mulher, nos termos desta Lei, o juiz poderá aplicar, de imediato, ao agressor, em conjunto ou separadamente, as seguintes medidas protetivas de urgência, entre outras:

1. suspensão da posse ou restrição do porte de armas, com comunicação ao órgão competente, nos termos da Lei $n^{\circ}$ 10.826, de 22 de dezembro de 2003;

II. afastamento do lar, domicílio ou local de convivência com a ofendida;

III. proibição de determinadas condutas, entre as quais:

a. aproximação da ofendida, de seus familiares e das testemunhas, fixando o limite mínimo de distância entre estes e o agressor;

b. contato com a ofendida, seus familiares e testemunhas por qualquer meio de comunicação;

c. frequentação de determinados lugares a fim de preservar a integridade física e psicológica da ofendida;

IV. restrição ou suspensão de visitas aos dependentes menores, ouvida a equipe de atendimento multidisciplinar ou serviço similar;

V. prestação de alimentos provisionais ou provisórios.

\section{[...]}

Das Medidas Protetivas de Urgência à Ofendida

Art. 23. Poderá o juiz, quando necessário, sem prejuízo de outras medidas:

I. encaminhar a ofendida e seus dependentes a programa oficial ou comunitário de proteção ou de atendimento;

II. determinar a recondução da ofendida e a de seus dependentes ao respectivo domicílio, após afastamento do agressor;

III. determinar o afastamento da ofendida do lar, sem prejuízo dos direitos relativos a bens, guarda dos filhos e alimentos;

IV. determinar a separação de corpos.

Art. 24. Para a proteção patrimonial dos bens da sociedade conjugal ou daqueles de propriedade particular da mulher, o juiz poderá determinar, liminarmente, as seguintes medidas, entre outras:

1. restituição de bens indevidamente subtraídos pelo agressor à ofendida;

II. proibição temporária para a celebração de atos e contratos de compra, venda e locação de propriedade em comum, salvo expressa autorização judicial;

III. suspensão das procurações conferidas pela ofendida ao agressor;

IV. prestação de caução provisória, mediante depósito judicial, por perdas e danos materiais decorrentes da prática de violência doméstica e familiar contra a ofendida.

Essas medidas possuem natureza jurídica de cautelar inominada, poderiam assim ser aplicadas pelo judiciário independente da Lei. Ao elencá-las, contudo, a Lei Maria da Penha dá visibilidade a essas possibilidades e contribui para sensibilizar as/os agentes do direito que atuam no processo e que devem orientar as muIheres sobre esse rol, desde a fase policial, perguntando quais as mesmas têm o desejo de requerer. Além disso, estipula-se que o/a juiz/a tem que decidir sobre as medidas protetivas, em 48 (quarenta e oito) horas, e oficiar ao Ministério Público, o que tenta garantir celeridade. Segundo Dias (2012), as medidas protetivas não são instrumento para assegurar processos, preparatórias de qualquer ação, mas têm como finalidade proteger direitos, evitando a continuidade da violência e das situações que a favorecem.

Estas medidas podem ser cumuladas com outras julgadas necessárias pelo julgador. 0 artigo 13 da Lei ainda prevê a possibilidade de aplicação, inclusive, quando for o caso da pessoa em situação de violência pertencer a algum outro grupo sujeito à proteção, de medidas previstas em outras normas como o Estatuto da Criança e do Adolescente (Lei 8.069/90) ${ }^{20}$ ou o

20 Este prevê como medidas de proteção, como exemplo: Art. 101. Verificada qualquer das hipóteses previstas no art. 98, a autoridade competente poderá determinar, dentre outras, as seguintes medidas: I - encaminhamento aos pais ou responsável, mediante termo de responsabilidade; II - orientação, apoio e acompanhamento temporários; III - matrícula e frequência obrigatórias em estabelecimento oficial de ensino fundamental; IV - inclusão em programa comunitário ou oficial de auxílio à família, à criança e ao 
Estatuto do Idoso (Lei n $\left.{ }^{\circ} 10.741 / 03\right) .{ }^{21}$

Ressalte-se, todavia, que sua natureza é de caráter provisório, devendo perdurar até subsistir sua motivação e até a decretação da sentença definitiva. Até lá podem ser revistas, cassadas ou substituídas por outras a qualquer tempo (art. 19). Seu impacto então na proteção na vida das mulheres dependerá da estrutura policial e judicial disponível que deve garantir: a devida orientação às mulheres sobre sua possibilidade, celeridade no julgamento e o monitoramento de sua implementação.

\section{Os centros especializados para mulheres em situação de violência e o surgimento do Pro Paz Mulher}

Nos termos da Lei Maria da Penha, a atuação das Varas de Juizado de Violência Doméstica e Familiar contra a Mulher deve ser articulada com outros serviços de modo a assegurar às mulheres condições para romper a situação de violência em que se encontram, possibilitando o acesso aos seus direitos. Uma das principais políticas de prevenção às violências cometidas e assistência às mulheres são os Centros de Referência. De acordo com a Norma Técnica de Uniformização dos Centros de Referência de Atendimento à Mulher em Situação de Violência (SPM, 2006b, p. 28):

Os Centros de Referência de Atendimento à Mulher em situação de violência são equipamentos da política pública especial de prevenção e enfren-

adolescente; $\mathrm{V}$ - requisição de tratamento médico, psicológico ou psiquiátrico, em regime hospitalar ou ambulatorial; VI - inclusão em programa oficial ou comunitário de auxílio, orientação e tratamento a alcoólatras e toxicômanos; VII - acolhimento institucional; VIII - inclusão em programa de acolhimento familiar; IX - colocação em família substituta.

210 Estatuto traz, por exemplo, no artigo 45 a possibilidade de: Art. 45. Verificada qualquer das hipóteses previstas no art. 43, o Ministério Público ou o Poder Judiciário, a requerimento daquele, poderá determinar, dentre outras, as seguintes medidas: I - encaminhamento à família ou curador, mediante termo de responsabilidade; II - orientação, apoio e acompanhamento temporários; III - requisição para tratamento de sua saúde, em regime ambulatorial, hospitalar ou domiciliar; IV - inclusão em programa oficial ou comunitário de auxílio, orientação e tratamento a usuários dependentes de drogas lícitas ou ilícitas, ao próprio idoso ou à pessoa de sua convivência que lhe cause perturbação; V - abrigo em entidade; VI - abrigo temporário. tamento à violência contra a mulher, vinculam-se administrativamente ao órgão gestor das políticas para as mulheres do município onde estão localizados, que tem como finalidade, encaminhar para atendimento e/ou atender a mulher em situação de violência e fornecer subsídios técnicos e estatísticos sobre a questão da violência contra a mulher para gestores das políticas públicas básicas e especiais, bem como para profissionais, representantes de organizações e comunidade em geral.

O primeiro centro de referência no país para muIheres em situação de violência foi a Casa Eliane de Grammont/SP, em 09 de março de 1990. Com a criação da Secretaria de Política para as Mulheres, esses equipamentos passaram de 36 (trinta e seis), em 2003, para 213, em 2011, o que ainda é insuficiente, levando-se em conta a dimensão do país (Cortês et al, 2012). Os Centros de Referência são mecanismos fundamentais de apoio à mulher e a seus filhos/as que muitas vezes são esquecidos nas andanças pelas instituições, sofrendo com os conflitos familiares e com o descaso institucional.

No Pará, uma das primeiras experiências de centro especializado no atendimento de mulheres em situação de violência, nos moldes trazidos pela Lei Maria da Penha, foi inaugurado em 8 de março de 2008, o Centro "Maria do Pará"22, inserido na estrutura da Coordenadoria Estadual da Mulher, vinculado à Secretaria Estadual de Justiça Direitos Humanos (SEJUDH). O Centro possuía como missão principal o atendimento humanizado que se integrasse com outros serviços da rede de proteção das mulheres.

O Centro de Referência Maria do Pará atendia demandas espontâneas e encaminhadas por outros serviços como: DEAM, Promotoria, Defensoria, Coordenadoria e Central 180 do governo federal. 0 Centro era voltado às mulheres em situação de violência através de uma equipe multiprofissional composta por: quatro psicólogas, duas assistentes sociais, pedagoga, enfermeira, massoterapeuta, socióloga e terapeuta ocupacional sendo que o atendimento poderia ser individual ou grupal. No atendimento grupal eram feitos grupos de reflexão e terapêutico ocupacional (Pinheiro, 2017).

22 Endereço: Avenida Serzedelo Corrêa, n. 956. 


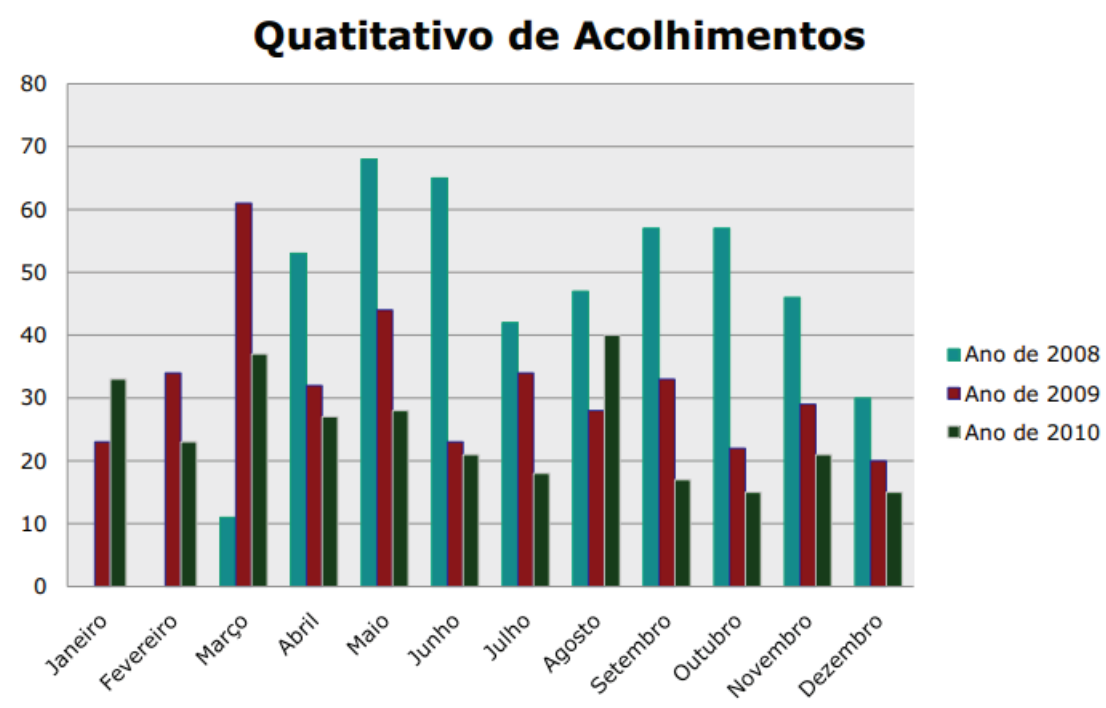

Um dos diferenciais do serviço era que, além de oferecer a assistência jurídica, de saúde e social, disponibilizava atendimento para as crianças, filhas/os das mulheres (Pinheiro, 2017). Ressalte-se que, apesar do projeto prever o atendimento jurídico, somente depois de um ano de funcionamento a defensoria passou a prestar atendimento uma vez por semana, reafirmando-se como mais um serviço psicossocial.

O Maria do Pará foi implementado em onze municípios que foram escolhidos a partir de um diagnóstico feito pelo governo Ana Júlia Carepa baseando-se nas maiores incidências de violação dos direitos das mulheres: Ananindeua, Belterra, Abaetetuba, Breves, Jacundá, Xinguara, Santarém, Itaituba, Parauapebas, Tucuruí. ${ }^{23}$

Esses centros receberam críticas pelo fato de funcionarem em local distante dos demais serviços e oferecer um atendimento psicossocial sem articulação com o que era oferecido em outros espaços (Souza, 2009). Isso levou a uma queda na demanda, conforme gráfico abaixo ${ }^{24}$, que demonstra uma diminuição para a metade do número dos acolhimentos de dezembro de 2008 a dezembro de 2010.

23 Disponível em http://sistema3.planalto.gov.br/spmu/atendimento/busca_subservico.php?uf=PA\&cod_subs=4. Acesso em: 12 jun. 2018.

24 Disponível em: http://www.ufpa.br/ics/arquivos/violencia_muIher/Centro_Maria_do_Para.pdf. Acesso em: 12 jun. 2018.
Cabe ressaltar que essa política foi desenvolvida por um governo estadual de esquerda entre anos de 2007 a $2010^{25}$, com o retorno, após as eleições de um partido opositor ${ }^{26}$ as ações do centro especializado, foram aos poucos sendo desarticuladas. O Governo do PSDB passou a associar os centros integrados a marca "Pro Paz", e em 2014 criou em Belém-PA o Pro Paz Mulher. ${ }^{27}$ Em municípios como Belém e Tucuruí, os antigos Centros Maria do Pará passaram a ser absorvidos pelo Pro Paz Mulher. Em outros municípios, como Capanema e Abaetetuba, foram transformados em Centros de Referência de Assistência Social. Na visita da Comissão Parlamentar Mista de Inquérito - CPMI de Violência contra Mulher, em Belém, foi denunciado pelos movimentos que "os Centros de Referência de Atendimento à Mulher estão sendo descaracterizados e fechados paulatinamente" (CPMI, 2013, p. 494).

De acordo com a coordenadora do Pro Paz Mulherre, no interior do Estado, todavia, há uma dinâmica diferente da capital, pois os espaços atendem mulheres

25 No governo de Ana Júlia (Partido dos Trabalhadores -PT), de 2007-2010.

26 Governo Simão Jatene (Partido Social Democrata BrasileiroPSDB), de 2011-2014.

27 Disponível em: http://jornaldetucurui.blogspot.com. br/2014/07/tucurui-governo-do-para-entrega-predio.html. Acesso em: 20 nov. 2017.

28 Entrevista realizada em 04 de abril de 2017. 
e crianças e adolescentes em situação de violência. Importante destacar que o Pro Paz Mulher, em Belém, atende mulheres de Ananindeua, Paragominas, Breves, Benevides, Icoaraci e de outros municípios da Região Metropolitana. Isso ocorre pela falta de estrutura no interior do Estado, algo que precisa ser pensado considerando as dimensões territoriais do Pará e as dificuldades impostas também pelos meios de transportes hidroviários para acessar alguns locais. Atualmente o atendimento especializado do Pro Paz Mulher chega ao interior do Pará por meio de seis núcleos distribuídos nas regiões do Xingu (Núcleo de Altamira), Guajarina (Núcleo de Paragominas), do Lago de Tucuruí (Núcleo de Tucuruí), Baixo Amazonas (Núcleo de Santarém), Bragantina (Núcleo de Bragança) e Marajó (Núcleo de Breves), além de contar com o suporte nas unidades da DEAM.

Em realidade, o Pro Paz tornou-se assim uma grande "marca" do Governo Simão Jatene, tanto que a coordenadora do comitê-gestor que o implementou foi sua filha, Izabela Jatene. Trata-se de uma experiência muito divulgada pelo Governo, como modelo de política pública. ${ }^{29}$ Essa experiência foi, inclusive, citada como exemplo de boa prática pela Organização das Nações Unidas (ONU), em Doha, no Qatar, durante o $13^{\circ}$ Congresso de Prevenção contra o Crime. De acordo com o Relatório do Comitê Permanente da América Latina para Prevenção de Delito (COPLAD, 2015), do Instituto Latino Americano das Nações Unidas (Ilanud), o Pro Paz: ${ }^{30}$

Oferece uma perspectiva de prevenção de espectro amplo, indo além de uma visão repressiva, propondo ações que dão maior ênfase em aspectos como a abertura de oportunidades para a população e acesso a serviços de saúde, educação em espaços mais adequados para o desenvolvimento de um te-

29 G1. Lei Maria da Penha completa 11 anos e Pará se destaca com atendimento integrado a vítimas. Disponível em: https://g1.globo. $\mathrm{com} / \mathrm{pa} / \mathrm{para} /$ noticia/lei-maria-da-penha-completa-11-anos-e-para-se-destaca-com-atendimento-integrado-a-vitimas.ghtml. Acesso em: 12 jun. 2018.

30 PROPAZ. Pro Paz - mais de 10 anos de atenção à pessoa em situação de vulnerabilidade social no Estado do Pará. Disponível em: <http://www.propaz.pa.gov.br/?q=pt-br/content/pro-paz-\%E2\%80\%93-mais-de-10-anos-de-aten \%C3\%A7\%C3\%A3o-\%C3\%A0-pessoa-em-situa\%C3\%A7\%C3\%A3o-de-vulnerabilidade-social-no-0 . Acesso em: 12 jun. 2018. cido social mais apropriado para a prevenção da violência, ao mesmo tempo em que se reforçam ações dirigidas para o fomento de uma cultura de paz, medida que se ganha cada vez mais espaço no conjunto das estratégias preventivas.

Não há clareza, contudo, sobre as perspectivas adotadas para conceitos como "cultura de paz" ou os desenhos institucionais que o envolvem. Isso torna mais curiosa a proporção que esta política pública ganhou nos últimos tempos, principalmente de 2012 até aqui. Isso demonstra, por um lado, a possibilidade de interiorização e institucionalização das políticas, mas, por outro, apresenta também como se delineiam as estratégias de governança no Estado. Estas são muitas vezes pautadas por arranjos que privilegiam projetos particulares, de um partido ou pessoa (ou família), fugindo aos ditames constitucionais da supremacia do interesse público e da eficiência na gestão das políticas ${ }^{31}$, que terminam constantemente reconstruídas ou descontinuadas. Deve-se compreender que a capacidade de um governo não é medida somente pelos resultados das políticas, mas também pela forma de exercício do poder (Gonçalves, 2006).

\section{Do setor social ao Pro Paz Mulher: permanências e limites de uma política}

Para analisar a atuação do Pro Paz Mulher é importante compreender o contexto de surgimento da DEAM. O Pará criou uma das primeiras delegacias da mulher do país. A primeira Delegacia da Mulher foi criada em São Paulo, em 1985, alastrando-se pelo país ao longo dos anos 80-90, como forma de prestar atendimento mais adequado às mulheres em situação de violência. Em Belém, em 1987, foi criada a Divisão de Crimes contra a Integridade da Mulher (DCCIM), como um setor especializado da Polícia Civil, atuando como correia de transmissão entre os serviços de polícia e o sistema judiciário (Souza, 2009).

A DCCIM funcionava no Bairro do Marco, na Travessa Vileta, distante dos principais serviços para a mulher

31 Art. 37, CF: A administração pública direta e indireta de qualquer dos Poderes da União, dos Estados, do Distrito Federal e dos Municípios obedecerá aos princípios de legalidade, impessoalidade, moralidade, publicidade e eficiência e (...). 
em situação de violência como o Instituto de Perícias Cientificas Renato Chaves, o Fórum Criminal, o Ministério Público ou a Defensoria Pública. Isso trazia grandes obstáculos e desestímulo às mulheres que precisam enfrentar grandes deslocamentos para fazer o exame de corpo de delito, para ir ao hospital ou aos órgãos de prestação jurisdicional.

Em 2006, através do Decreto governamental $n^{\circ} 2690$, a DCCIM passou a ser DEAM (Divisão Especializada no Atendimento à Mulher), visando adequar-se ao formato nacional. Nesse ano, a Secretaria Especial de Políticas para as Mulheres da Presidência da República (SPM/PR) iniciou um esforço de uniformização diante da diversidade e desarticulação entre as delegacias da mulher criando uma Norma Técnica de Padronização das Delegacias Especializadas de Atendimento à Mulher - DEAMs, em 2006 (SPM, 2006a).

A proposta de implementação de uma norma técnica de padronização das Delegacias insere-se no desafio de implantação da Política Nacional de Enfrentamento à Violência contra a Mulher, definindo normativas quanto: às atribuições das Delegacias e à necessidade de coordenação específica; às diretrizes, aos fluxos e procedimentos de atendimento; à estrutura organizacional; à formação de recursos humanos; à infraestrutura e, finalmente, ao seu papel na implementação e participação na Rede de Atendimento.

Em realidade, a DCCIM encontrou grandes dificuldades para se adequar às Normas Técnicas e se transformar em uma DEAM. A Delegacia possuía um modelo que passou a ser muito criticado pelos movimentos de mulheres pois comportava em um mesmo espaço: uma triagem, um setor social, um setor policial, um abrigo para mulheres ameaçadas de morte (Unidade de Acolhimento Temporário - UAT) ${ }^{32}$ e a carceragem para os homens que abrigava também presos trazidos de outras delegacias.

A antiga DEAM-Belém funcionava em um prédio cedido pela Secretaria de Estado de Desenvolvimento Social (SEDES), o que era um problema, porque além de

32 O fato do abrigo ser no mesmo prédio que a carceragem colocava em risco a vida das abrigadas. Havia, inclusive, uma janela que permitia aos presos verem as mulheres que lá estavam. não ter sido projetada para ser uma delegacia especializada, se distanciava das normas técnicas direcionadas para delegacias de atendimento às mulheres. Além disso, abrigava no mesmo espaço a delegacia e o abrigo, o que era um contrassenso, uma vez que, um abrigo dessa natureza deve necessariamente ser mantido em local sigiloso. Tais problemas se somavam a escassez de recursos humanos e desorganização no atendimento, a triagem, por exemplo, poderia ser realizada por qualquer funcionário presente, inclusive um profissional da segurança.

As mulheres, ao chegarem à delegacia, ficavam em uma sala de espera. Após um longo tempo, em regra, seriam atendidas pela triagem que as encaminhava para o setor policial, vinculado à Secretaria de Estado de Segurança Pública (SEGUP), onde fariam a ocorrência. Algumas mulheres, contudo, eram direcionadas a um setor social, vinculado à SEDES, onde seriam atendidas por profissionais da Psicologia e do Serviço Social. Percebia-se nesse momento uma seleção arbitrária entre o que era crime e o que era "apenas" considerado pela equipe da delegacia como "briga de marido e mulher".

Para Luanna Souza (2009), percebia-se neste setor uma tentativa de impedir a via judicial, buscando, quando possível, a resolução extrajudicial do conflito. Muitas mulheres acabavam "desistindo" da ocorrência para que algum profissional do setor "conversasse" com seu companheiro. Eram muitas vezes questionadas se "queriam mesmo fazer aquilo", se compreendiam que o marido ia ficar "com a ficha suja”. Caso decidissem pelo registro seriam encaminhadas para o setor policial. Antes, entretanto, iriam para outra sala de espera. Isso terminava desestimulando muitas mulheres a registrar a ocorrência e dar prosseguimento aos atendimentos.

Outro aspecto a ser ressaltado, segundo Conrado (2005), é a "psicologização do atendimento", que pode significar mais um obstáculo à efetivação dos direitos das mulheres nessa condição. Muitas mulheres relatavam nesses atendimentos o reforço de estereótipos como "bom pai", "trabalhador", "provedor", "bom marido", e de um discurso sobre "pensar e refletir sobre o que ela realmente quer fazer com o homem que ama”. Essa lógica pautada na “preservação da 
família" e que acaba minimizando a violência, ainda está presenta em muitos espaços, como cultura institucional, em que pese as críticas dos movimentos.

Interessante notar que cada setor era vinculado a uma secretaria diferente e possuía dinâmicas diferentes o que gerava muitos conflitos, inclusive sobre para qual setor a mulher deveria iniciar o atendimento. Os conflitos aconteciam desde as coisas mais simples e operacionais, como quem comprava a água, até a falta de planejamento e diálogo na estruturação na delegacia de forma geral.

Ademais, a delegacia estava localizada em um prédio muito velho, com graves problemas estruturais, o que potencializava esses conflitos. Questões assim demarcam as especificidades dos entraves para implementação da Lei Maria da Penha no Estado, pois se a maior concentração de investimentos e serviços para as mulheres em situação de violência estava na capital e ainda assim a DEAM- Belém apresentava-se nessas circunstâncias, imaginem-se as condições e o acesso aos serviços pelas mulheres das cidades mais distantes do estado. As dimensões territoriais e de locomoção também são um entrave para expansão dos serviços para os interiores.

Em 01 de julho $2014^{33}$, foi inaugurada a nova sede da DEAM. O prédio foi projetado e iniciado pelo governo Ana Júlia, mas foi concluído e inaugurado pelo governo Simão Jatene em 01 de julho 2014, vinculado ao Programa Pro Paz Mulher. Como já descrito este programa procura articular ações de polícia, de perícia, atendimento psicossocial e outros serviços à mulher em situação de violência em um único endereço ${ }^{34}$. Nesse espaço passou a ser oferecido, o atendimento policial pela DEAM; o psicossocial; a perícia criminal do Centro de Perícias Científicas "Renato Chaves"; sala de atendimento para a Defensoria Pública e sala de audiências. ${ }^{35}$

33 Endereço: Travessa Mauriti nº 2394 - Bairro Marco. Município: Belém.

34 Atualmente o programa Pro Paz Mulher atende nos municípios de Belém, Bragança, Paragominas, Tucuruí, Santarém, Altamira. 35 AGENCIA PARÁ. Pro Paz Mulher oferece atendimento integrado a vítimas de violência. Disponível em: http://www.agenciapara.com. br/noticia.asp?id_ver=102924._Acesso em: 12 jun. 2018.
A proposta seria de que a mulher passasse por todos os serviços, mas boa parte destes não estava funcionando no momento da inauguração, centrando-se basicamente no atendimento policial e psicossocial. A escassez de recursos humanos fica evidente em um prédio de três andares onde há áreas equipadas para diversos serviços como: brinquedoteca, sala multiuso, auditório e espaços específicos destinados aos atendimentos jurídicos, periciais e psicossociais sendo que algumas destas salas não são utilizadas por falta de profissionais como, por exemplo, a brinquedoteca.

Em que pese o projeto seja ousado ao unir todos esses serviços, retoma-se a dinâmica anterior da DCCIM onde primeiro a mulher realizava o atendimento social e depois era encaminhada para o setor policial, o que aumentava o tempo na delegacia. Segundo a delegada entrevistada ${ }^{36}$, isso tem causado insatisfação nas mulheres que querem ser atendidas imediatamente pela polícia, o que provoca desistência da ocorrência, por parte das mulheres devido à demora nesse fluxo. Seria fundamental a estruturação de um protocolo que delimitasse melhor o curso do atendimento e o papel de cada setor.

Outro problema é a vinculação do atendimento. A mulher que se dirige até DEAM tem, em regra, a expectativa do atendimento policial. Fica frustrada, nesses termos, quando há demora no atendimento em outro serviço, embora num mesmo espaço de funcionamento. Os Centros de Referência precisam assim funcionar de forma autônoma, sendo a mulher encaminhada após o atendimento policial. De acordo com as Normas Técnicas das DEAMs: "O atendimento inicial e o acolhimento devem ser feitos por uma equipe de policiais qualificados profissionalmente, preferencialmente do sexo feminino, com compreensão do fenômeno da violência de gênero" (SPM, 2006a, p.36).

A DEAM pode encaminhar a mulher ao Centro de Referência que atende à demanda espontânea, que independe da situação criminal, e às mulheres encaminhadas de outros serviços. Ela deve, contudo, manifestar interesse de ser atendida pelo Centro de Referência: "A mulher em situação de violência que

36 Entrevista realizada em 20 de abril de 2017. 
manifeste o desejo de ser atendida pelo Centro de Referência será encaminhada ao atendimento inicial que será realizado por uma dupla de profissionais composta por um(a) psicólogo(a) e um(a) assistente social” (SPM, 2006b, p.33).

Além do acolhimento e do atendimento inicial (diagnóstico inicial), a metodologia de funcionamento dos Centros de Referência preveem a etapa de "diagnóstico aprofundado e atendimento" e de "monitoramento do atendimento e encerramento do atendimento" (SPM, 2006b). Observa-se, contudo, no Pro Paz Mulher uma descontinuidade do atendimento, que acaba envolvendo somente as primeiras etapas, no momento após o fato, o que revela a fragilidade do serviço oferecido (Souza, 2016).

Ainda de acordo com a Norma Técnica, o desligamento do serviço de atendimento especializado somente deveria ocorrer quando fosse verificada a superação da situação de violência, o fortalecimento de mecanismos psicológicos e sociais que tornem viáveis a autodeterminação da mulher. A ideia de oferecer apenas um acolhimento inicial fere a ideia do Centro de ser um espaço mais contínuo de atendimento. Além disso, uma das diretrizes estabelecidas pela Norma Técnica também seria a construção de um Plano de segurança pessoal para a mulher em situação de violência, o que não tem sido realizado.

Percebe-se assim uma continuidade do que antes se via no setor social, sem uma análise adequada do funcionamento desses serviços, tendo sido apenas repaginado. $\mathrm{O}$ atendimento jurídico ainda é limitado, sendo oferecido pela Defensoria Pública em alguns dias estabelecidos e somente em alguns tipos de ação. Ainda são serviços autônomos, com diferentes horários de funcionamento e coordenações, mas dividindo o mesmo prédio, só que em melhores condições.

Segundo a coordenadora do Pro Paz Mulher ${ }^{37}$, o fato de ter uma sala do Poder Judiciário e do Ministério Público não garante integração com os órgãos de justiça, pois cada um tem o seu sistema e sua dinâmica de atendimento. O Judiciário passou a atuar no espaço mais recentemente e tem como foco o julgamento

37 Entrevista realizada em 04 de abril de 2017. das medidas protetivas, através de alguns servidores/ as que recolhem a demanda para encaminhar aos juízes/as nas varas e ao Ministério Público. Ocorre que, além de não haver a devida integração essa relação muitas vezes subverte o papel do serviço. Segundo a coordenadora é comum que seja solicitado às profissionais do Centro laudos para a produção de provas:

(...) tem a questão de produzir provas né, a gente precisa produzir provas para que ele criminoso, aquele que cometeu a agressão seja responsabilizado, né, a gente precisa fazer que eles sejam responsabilizados, mas talvez em cima das consultas não consiga produzir essa prova, eu preciso de dez, ou as vezes, eu não faço atendimento, quem faz são elas, eu só escuto elas falando, as vezes no primeiro atendimento você já pá, tá tudo revelado ali, é mais difícil com criança, mas com mulher também acontece dessa forma, no primeiro atendimento tá, mas às vezes tu vai com cinco atendimentos e não consegue produzir prova e o ministério público diz assim, mas eu preciso que vocês me deem provas porque senão a gente vai ter que revitimar porque eu vou, mas as coisas não são mecânicas assim dessa forma (sic).

O Pro Paz Mulher assume assim ora o papel de "setor psicossocial" da DEAM, ora do Judiciário. Entretanto, mais do que um setor psicossocial, os Centros de Referência deveriam assumir o papel de articuladores dos serviços dos organismos governamentais e não-governamentais que integram a rede de atendimento às mulheres em situação de vulnerabilidade social oferecendo: a) Aconselhamento em momentos de crise, b) Atendimento psicossocial, c) Aconselhamento e acompanhamento jurídico, d) Atividades de prevenção, e) Qualificação de profissionais, f) Articulação da rede de atendimento local, g) Levantamento de dados locais sobre a situação da violência contra a mulher (SPM, 2006b).

Uma parte dos problemas de sua implementação decorre da falta de monitoramento e transparência do serviço. Segundo Izumino (2014), esse é um problema nacional que impede o monitoramento dos serviços. De acordo com a Norma Técnica dos Centros de Referência (2006) uma das diretrizes dos centros deveria ser a gestão democrática e o envolvimento de mulheres no monitoramento das ações. 
O diálogo com a sociedade civil colaboraria com essa maior atenção às mulheres que são historicamente invisibilizadas, contudo, percebe-se que até os movimentos de mulheres foram alijados dos processos decisórios, uma vez que na inauguração do novo prédio onde funciona hoje o Pró paz Mulher e a DEAM ${ }^{38}$ não havia um único movimento representado, mesmo diante da relação histórica entre os movimentos de mulheres e as DEAMs que cobravam sua criação e sempre a monitoraram (Souza, 2016).

Essa forma de tratamento contradiz inclusive com o papel atribuído pela Lei Maria da Penha aos movimentos sociais. Esta inovou ao reconhecê-los como agentes de defesa dos interesses por ela assegurados (art.37). A SPM (2011b) até inclui os movimentos dentro da compreensão de rede de enfrentamento entendendo ser esta composta por agentes governamentais e não-governamentais formuladores, fiscalizadores e executores de políticas voltadas para as mulheres (tais como organismos de políticas para as mulheres, ONGs feministas, movimento de mulheres, conselhos dos direitos das mulheres, outros conselhos de controle social).

A falta de compreensão sobre o papel da sociedade civil faz com que suas demandas tenham pouca força política e dependam de intenso diálogo e articulação com as demais entidades e isso enfraquece as políticas públicas que ficam somente à mercê da avaliação de seus gestores quando deveriam ser públicas. Esse foi o paradigma da Constituição Federal de 1988 que afirmou a participação popular e o exercício do controle social nas políticas públicas. Neste contexto de ampliação dos direitos sociais, a interferência política da sociedade civil nas decisões tomadas pelo Estado torna-se instrumento fundamental de fortalecimento democrático.

A relação com os movimentos e o diálogo com as mulheres pode contribuir também para fortalecer a perspectiva de gênero e feminista do espaço. Um dos

38Antes de ser inaugurado o novo Prédio que abriga hoje o Propaz-Mulher na parte da frente e a DEAM na parte de trás, a Delegacia funcionava juntamente com a casa abrigo em um prédio cedido pela SEDES (Secretaria de Desenvolvimento e Assistência Social) em condições de precariedade e incompatibilidade com as Normas Técnicas. objetivos dos Centros deve ser "construir um atendimento que questione as relações de gênero" (SPM, 2006b). Ainda se observa no espaço a dificuldade de estruturação de uma política que efetivamente confronte as relações de gênero existentes em nossa sociedade, apresentando-se mais como uma política pública para mulheres do que uma política pública de gênero. Para Bandeira (2005), em que pese às demandas feministas, as políticas públicas no Brasil, no geral, quando são feitas e dirigidas às mulheres não contemplam necessariamente a perspectiva de gênero, reproduzindo papéis e estereótipos sem considerar a diversidade dos processos de socialização para homens e para mulheres.

Também se observa a falta de atenção às questões de raça, etnia, geração, ainda prevalecendo uma visão universal de mulher, o que se torna muito problemático em especial em uma região que contempla tamanha diversidade e que deveria ter políticas alcançando desde as mulheres indígenas a ribeirinhas. Segundo o Mapa da Violência de 2015 a violência tem aumentado para as mulheres negras e diminuído para as mulheres brancas ${ }^{39}$, o que mostra a dimensão racial do problema. Kimberlé Crenshaw (1991) formula a interseccionalidade como uma teoria a qual explica o fato da mulher negra sofrer duplamente os impactos das injustiças sociais, pois está submetida a duas condições: gênero e raça.

Outro aspecto importante a ser mencionado se refere ao fato de que, em Belém, foram notificados 8866 casos de violência, entre os anos de 2014 a 2016, segundo informações do Departamento de Vigilância em Saúde (DEVS) do município, sendo que em 86,9\% dos casos a vítima era do sexo feminino e cerca da metade (51,6\%) atingiu mulheres adultas (18 anos ou mais). Da violência contra mulheres adultas, o Pro Paz Mulher notificou 81,2\% dos casos. ${ }^{40}$ Esse perfil demonstra a importância desse serviço para dimensionar a magnitude da violência na região, bem como para dar subsídios para elaboração de políticas pú-

39 Mapa da violência 2015. Disponível em: <http://www.mapadaviolencia.org.br/pdf2015/MapaViolencia_2015_mulheres.pdf>. Acesso em: 12 jun. 2018.

40 Todos os dados foram coletados por Veloso, Magalhães e Cabral, I.R (2016), a partir das informações disponibilizadas pelo Departamento de Vigilância em Saúde (DEVS) do município de Belém-PA. 
blicas de enfrentamento da violência, em especial da violência contra a mulher. Além disso, é válido considerar que, no que tange às diretrizes das portarias do Ministério da Saúde sobre a notificação dos casos, o Pro Paz Mulher vem respondendo às exigências adequadamente, visto que em Belém, atualmente, é o serviço que mais realiza a notificação de violência. ${ }^{41}$

Cabe ainda destacar, que o Pro Paz Mulher, segue o padrão do Pro Paz Integrado, que funciona na Santa Casa de Misericórdia do Pará, com o atendimento de crianças e adolescentes em situação de violência e tem entre seus protocolos o preenchimento da Ficha de Notificação de Violência Interpessoal/ Autoprovocada (Portaria GM/MS n ${ }^{\circ} 1271 / 2014$ ), tal como os serviços de saúde do município.

No entanto, vale considerar que a inserção deste tema na agenda do setor saúde no Município de Belém-PA se iniciou em 2009 e a subnotificação dos casos de violência ainda é um problema a ser enfrentado tanto em Belém como em outras capitais do país, além disso, a implantação da notificação, trouxeram resultados positivos no tocante à sistematização e visibilidade dos casos (Veloso et al., 2013), mas a prevenção primária não vem ocorrendo como deveria, como fica evidente ao se ver o número de casos de violência notificados pelo Pro Paz Mulher, mencionado acima.

Segundo Veloso, Magalhães e Cabral (2016) e Souza et al. (2014), a partir da notificação, é esperado que se realize o acompanhamento ampliado dos casos, procedimento que constitui uma importante estratégia de cuidado e proteção às vítimas, além do que representa um poderoso instrumento de planejamento, uma vez que ajuda a dimensionar a questão e determinar a necessidade de investimentos em núcleos de vigilância e assistência. Uma vez identificado o caso é fundamental que se realize uma intervenção interdisciplinar e parcerias institucionais, cujas ações são imprescindíveis para a resolutividade dos atendimentos.

41 A notificação das violências é contemplada na Portaria GM/MS $n^{\circ} 1.271 / 2014$, de modo a atender a obrigatoriedade prevista no Estatuto da Criança e do Adolescente (ECA), instituído pela Lei $n^{\circ}$ 8.069/1990; no Estatuto do Idoso instituído pela Lei n ${ }^{\circ} 10.741 / 2003$ e alterado pela Lei ${ }^{\circ} 12.461 / 2011$; e na Lei $n^{\circ} 10.778 / 2003$, que institui a notificação compulsória de violência contra a mulher.
Por fim, é importante comentar que o Núcleo Especializado de Atendimento ao Homem em Violência Doméstica e Familiar (NEAH) não mantém ações diretamente articuladas com o Pro Paz Mulher, o que também demonstra a necessidade de articulação desses serviços. O referido núcleo foi criado por meio do Convênio $n^{\circ}$ 135/2010 entre o Ministério da Justiça, o Departamento Penitenciário Nacional -DEPEN e Defensoria Pública do Estado do Pará, em janeiro de 2011, com o objetivo de realizar atendimento especializado ao Homem Autor de Violência Doméstica e Familiar contra a Mulher, na área jurídica e psicossóciopedagógica, de forma a evitar a reincidência criminal, em cumprimento ao art. 35 da Lei Maria da Penha e funciona nas dependências da Defensoria Pública.

\section{Considerações finais}

A Lei Maria da Penha trouxe um importante horizonte ao preconizar a criação dos Centros integrados de atendimento às mulheres em situação de violência. Contudo as alternâncias e descontinuidades dos modelos de governança tanto no estado do Pará, quanto no país, produzem e reproduzem engrenagens que em muitos casos impedem o avanço e a consolidação de políticas de estado mais perenes e efetivas. Por outro lado, são diversas as combinações de lógicas globais, distantes e locais, que muitas vezes não dialogam.

É fundamental que esse equipamento, bem como os demais que compõem a Rede de Atendimento à Mulher em Situação de Violência atue efetivamente de forma a consolidar a implementação de uma política nacional de enfrentamento à violência contra a mulher. É necessário, para tanto, que se alcance uma padronização de diretrizes e procedimentos de funcionamento do serviço, assegurando o controle e o monitoramento e a produção nacional de dados.

A Norma Técnica de uniformização dos centros de referência de atendimento à mulher em situação de violência trouxe um importante esforço que ainda encontra muitas dificuldades para ser operacionalizada no Estado. O atual modelo de governança, em especial a gestão da Fundação Pro Paz deveria estreitar a relação com os movimentos de mulheres que historicamente tem realizado o debate sobre o enfrentamento da violência de gênero. 
No Pará, o Pro Paz Mulher, tem se implementado enquanto modelo de Centro integrado, e de fato trouxe melhores condições para o atendimento psicossocial que era realizado nas DEAMs. O PPM, contudo, se revela enquanto um serviço amplo, que se diversifica nas propostas de atendimento mantendo a ideia de integração, mesmo que esta não se cumpra na prática. Distancia-se, desta forma, do que deveria ser um Centro Integrado de Atendimento. Não se implementou de fato uma ruptura com o modelo de "setor psicossocial" que funcionava no antigo prédio, tendo sido apenas repaginado. Para que um centro integrado funcione ele deve oferecer mais do que o atendimento psicossocial e policial. Precisa ser um espaço de articulação inter e intrassetorial de políticas sociais que possam dar respostas mais efetivas ao fenômeno da violência.

Se de um lado percebemos continuidades, verificamos também descontinuidades que prejudicam o aprimoramento dos centros integrados, como foi o caso do Maria do Pará. As mudanças de governo levaram ao descarte de políticas que estavam sendo desenvolvidas, o que compromete os avanços e aumenta a demanda de recursos para uma "nova” rede de articulação.

Os Centros Integrados também não podem funcionar como se fossem uma extensão das DEAMs, que tem outras lógicas de funcionamento. Assim uma mulher pode não ter um boletim de ocorrência, mas requerer o atendimento no Centro. Este precisa ter mais autonomia até para se desenvolver enquanto um espaço articulador da rede de enfrentamento à violência como um todo e uma política pública que afronte as desigualdades de gênero.

É também fundamental que esses serviços tenham um olhar para as dimensões de raça, classe, etnia, regionalidade, além de outros marcadores, para compreender as violências sofridas pelas mulheres na região e diversificar as estratégias de enfrentamento evitando a incorporação de noções como "cultura de paz" que não são devidamente problematizadas.

Os dados mais recentes sobre a violência que atinge as paraenses denunciam os limites das políticas públicas estaduais. No ano de 2017, o estado encabeçou o ranking nacional que numera as cidades mais violentas para as mulheres, onde o município de Ananindeua, que fica na região metropolitana, apareceu no topo da lista dos lugares com maior taxa de morte apresentando 21,9 homicídios para cada 100 mil muIheres e um crescimento de $730 \%$ comparado com o ano de $2005 . .^{42}$

É de fundamental importância de construir mecanismos que democratizem a gestão desses espaços e permitam seu monitoramento para que essa política seja conduzida com maior transparência. Isso vai contribuir para que as demandas das mulheres sejam efetivamente alcançadas em uma lógica ativa de cidadania.

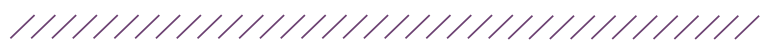

42 APUBLICA. Violência contra a mulher no Brasil. Disponível em: https://apublica.org/a-cidade-que-mais-mata-mulheres-no-brasil/. Acesso em: 12 jun. 2018. 


\section{Referências}

Bandeira, L. (2005). Fortalecimento da Secretaria Especial de Políticas para as Mulheres avançar na transversalidade da perspectiva de Gênero nas Políticas Públicas. Brasília: SPM.

Bianchini, A. (2014). Lei Maria da Penha: aspectos assistenciais, protetivos e criminais da violência de gênero. 2 ed. São Paulo: Saraiva.

Birol, J., \& Pedra, A. (2007, junho) Políticas públicas de prevenção da violência e a prevenção vitimária. In: Âmbito Jurídico, Rio Grande, X, n. 42. Disponível em: <http://www.ambitojuridico.com.br/site/ index.phpn_link=revista_artigos_leitura\&artigo_ id=1802 $>$. Acesso em: 12 jun. 2018.

Brasil, (2004). Secretaria Especial de Políticas Para às Mulheres - SPM. I Plano nacional de políticas para as mulheres. Brasília: SPM.

Brasil, (2006a). Secretaria Especial de Políticas Para às Mulheres - SPM. Norma técnica de padronização das delegacias especializadas de atendimento às mulheres. Brasília: SPM.

Brasil, (2006b). Secretaria Especial de Políticas Para às Mulheres - SPM. Norma técnica de uniformização dos centros de referência de atendimento à mulher em situação de violência. Brasília: SPM.

Brasil, (2007a). Secretaria Especial de Políticas Para às Mulheres - SPM. II Plano Nacional de Políticas para as Mulheres. Brasília: SPM.

Brasil, (2007b). Secretaria Especial de Políticas Para às Mulheres - SPM. Pacto Nacional de Enfrentamento à Violência contra a Mulher. Brasília: SPM.

Brasil, (2011a). Secretaria Especial de Políticas Para às Mulheres - SPM. Política nacional de enfrentamento à violência contra a mulher. Brasília: SPM.

Brasil, (2011b). Secretaria Especial de Políticas Para às Mulheres - SPM. Rede de enfrentamento à violência contra as mulheres Secretaria Nacional de Enfrentamento à Violência contra as Mulheres. Brasília.

Brasil, (2014). Secretaria Especial de Políticas Para às Mulheres - SPM. Termo de Referência - Enfrentamento da Violência contra as Mulheres. Brasília: SPM.

COPLAD. (2015). General Report of the Permanent Latin America Committee for Crime Prevention. Disponível em: https://www.unodc.org/documents/congress/Documentation/Report/ACONF222_17e_ V1502929.pdf. Acesso em: 13 jun. 2018
Conrado, M. (2005). Vergonha ou intimidação? Um retrato da violência cometida contra a mulher em Belém do Pará. Texto apresentado na VI Reunião de Antropologia do Mercosul, na Universidad de la República, Montevideo realizado nos dias 16, 17 e 18 de novembro, (mimeo).

Côrtes, G. R. (2012). A Informação no enfrentamento à violência contra mulheres: Centro de Referência da Mulher "Ednalva Bezerra": relato de experiência. Biblionline, João Pessoa, v. 8, n. esp. p.134-151.

CPMI, (2013) - Comissão Parlamentar Mista de Inquérito com a finalidade de investigar a situação da violência contra a mulher no Brasil e apurar denúncias de omissão por parte do poder público com relação à aplicação de instrumentos instituídos em lei para proteger as mulheres em situação de violência. Relatório Final. Disponível em: $<$ http://spm.gov.br/publicacoes-teste/publicacoes/2013/relatorio_cpmi_mulher-pdf-parte1>. Acesso em: 12 jun. 2018.

Crenshaw, K. W. (1991). Mapping the Margins: Intersectionality, Identity Politics, and Violence against Women of Color. Stanford Law Review, 43 (6). P. 1241-1299.

Dias, M. B. (2012) A Lei Maria da Penha na Justiça: a efetividade da Lei $n .^{\circ}$ 11.340/2006 de combate à violência doméstica e familiar contra a mulher. 3 ed. São Paulo: Revista dos Tribunais.

Gonçalves, A. (2006) O conceito de governança. In: Anais do CONPEDI Manaus. Disponível em: $<$ http://www.egov.ufsc.br/portal/sites/default/files/conceito_de_governanca.pdf> Acesso em: 12 jun. 2018.

Molina, A. G. de, \& Gomes, L. F. (2012) Criminologia. 8 ed. São Paulo: Revista dos Tribunais.

OBSERVE. (2011) Identificando entraves na articulação dos serviços de atendimento às mulheres vítimas de violência doméstica e familiar em cinco capitais. Relatório final. Salvador: UFBA.

Passinato, W. (2014) A CPMI da Violência contra a MuIher e os desafios para monitorar e avaliar a aplicação da Lei Maria da Penha. Disponível em: <http:// www.compromissoeatitude.org.br/a-cpmi-da-violencia-contra-a-mulher-e-os-desafios-para-monitorar-e-avaliar-a-aplicacao-da-lei-maria-da-penha-por-wania-pasinato/?print=1>. Acesso em: 12 jun. 2018.

Pinheiro, I. (2017) Um novo tempo para as paraenses? 
A agenda de governo de Ana Júlia Carepa e os recursos aplicados no enfrentamento da violência doméstica contra as mulheres (2007-2010). Trabalho de Conclusão de Curso, Ciências Sociais, UFPA. Belém.

Reis, A. A. dos. (2010) O atendimento psicológico às mulheres em situação de violência no Centro de Referência Maria do Pará: um balanço após dois anos de funcionamento. Revista NUFEN, 1(2), 2010. Disponível em: <http://pepsic.bvsalud. org/scielo.php?script=sci_arttext\&pid=S2175$-25912010000100008 \& \operatorname{lng}=p t \& n r m=i s o>$. Acesso em: 12 jun. 2018.

Santos, C. M. (2015) Curto-Circuito, falta de linha ou na linha? Tecendo a(s) rede(s) de enfrentamento à violência doméstica contra mulheres em São Paulo. Revista de estudos Feministas. 23(2), 577-600.

Souza, C. dos S. et al. (2014, março) Sistema de Vigilância de Violências e Acidentes/VIVA e a notificação da violência infanto-juvenil, no Sistema Único de Saúde/SUS de Feira de Santana-Bahia, Brasil. Ciências saúde coletiva, Rio de Janeiro, v. 19, n. 3, p. 773-784. Disponível em<http://www.scielo.br/ scielo.phpscript=sci_arttext\&pid=S141381232014 000300773\&lng=en\&nrm=iso>. Acesso em: 12 jun. 2018.

Souza, L. T. (2009) "Será que isso vai pra frente, doutora?” Caminhos para a implementação da Lei "Maria da Penha" em Belém. Dissertação de Mestrado. Orientação da Profa. Dra. Monica Prates Conrado. Programa de Pós-Graduação em Direito. Universidade Federal do Pará.

Souza, L. T. (2016) Da expectativa à realidade: a aplicação de sanções na Lei Maria da Penha. Rio de Janeiro: Lumen Juris.

Veloso, M. M. X. et al. (2013, maio) Notificação da violência como estratégia de vigilância em saúde: perfil de uma metrópole do Brasil. Ciênc. saúde coletiva. Rio de Janeiro, v. 18, n. 5, p. 1263-1272. Disponível em: <http://www.scielo. br/scielo.php?script=sci_arttext\&pid=S1413$-81232013000500011 \& \operatorname{lng}=e n \& n r m=i s o>$. Acesso em 19 Jun 2018. http://dx.doi.org/10.1590/ S1413-81232013000500011.

Veloso, M. M. X.; Magalhães, C. M. C., \& Cabral I. R. (2017) Identificação e notificação de violência contra crianças e adolescentes: limites e possibilidades de atuação de profissionais de saúde.
Revista Mudanças - Psicologia da Saúde, 25 (1), Jan.-Jun.

Winch, R. R., \& Escobar, G. V. (2012) Os lugares da muIher negra na publicidade brasileira. Cadernos de Comunicação. v.16, n.2, Jul-dez.

Data de submissão/Submission date: 23.03.2018.

Data de aceitação para publicação/Acceptance date: 24.06.2018. 